\title{
Livros Didáticos e a Importância no Discurso Social
}

Didactic Books and the Importance in Social Discourse

XAVIER R., Gabriela; Mestranda; Centro Universitário Ritter dos Reis

gabrielarangelxavier@gmail.com

\section{Resumo}

Este trabalho realiza uma reflexão acerca do impacto social presente no discurso dos livros didáticos distribuídos pelo Plano Nacional do Livro Didático (PNLD). Serão abordadas temáticas referentes às desigualdades de gênero, aos preconceitos raciais e questões sobre sexualidade, através dos estudos que evidenciam como estes assuntos se apresentam nas publicações didáticas ao longo dos anos. O Brasil é o país que mais distribui livros didáticos no mundo e o segmento movimenta bilhões de reais no mercado editorial, fatos estes que evidenciam a importância do estudo desta temática, bem como o impacto na vida do estudante da rede pública, que é o principal beneficiado deste sistema de distribuição. Pretende-se estabelecer argumentos que expõem a relevância social do livro didático, a importância do design gráfico e da filosofia do design, para a formulação e produção dos materiais didáticos. A metodologia utilizada para a realização deste estudo é de caráter bibliográfico e documental.

Palavras Chave: Livro Didático; PNLD; Cultura; Design Gráfico; Filosofia do Design.

\begin{abstract}
This work reflects on the social impact of the textbook discourse distributed by the National Textbook Plan (PNLD). It will be approached themes related to gender inequalities, racial prejudices and questions about sexuality, through the studies that show how these subjects are presented in didactic publications over the years. Brazil is the country that most distributes textbooks in the world and the segment moves billions of reais in the publishing market, facts that show the importance of the study of this subject, as well as the impact on the life of the student of the public network, which is the main benefited from this distribution system. It is intended to establish arguments that expose the social relevance of the textbook and the importance of the graphic design and the design philosophy for the formulation and production of didactic materials. The methodology used for the accomplishment of this study is of bibliographical and documentary character.
\end{abstract}

Keywords: Textbook; PNLD; Culture; Philosophy of Design. 


\section{INTRODUÇÃO}

O presente estudo propõe uma reflexão sobre questões referentes a cultura, a sociedade a educação e a importância social dos livros didáticos. Pretende dialogar sobre o impacto social do discurso das obras didáticas distribuídas pelo Plano Nacional do Livro Didático (PNLD), além de ressaltar evoluções e as conquistas deste segmento. O tema é de relevância social, tendo em vista que o Brasil é um dos países que mais distribui gratuitamente materiais didáticos e, estes livros representam grande parte da movimentação financeira, no mercado editorial do país.

Na perspectiva de Guattari e Rolnik (1996), este estudo desenvolve o conceito de cultura e cultura de massa e constrói algumas perspectivas no campo da educação. Além destas questões, o artigo discute alguns pontos sobre a filosofia do design (BECCARI, PORTUGAL e PADOVANI, 2017). Através dos editais do PNLD e de outros documentos oficiais, são abordadas temáticas de inclusão e, a partir de outros estudos direcionados (teses e dissertações) analisa-se a evolução no tipo de abordagem dos materiais didáticos. A metodologia utilizada para a realização desta pesquisa é de caráter é documental e bibliográfico (SAMPIERI, LUCIO E COLLADO, 2013), que buscou, através de livros, documentos, artigos (dos principais repositórios acadêmicos) e sites de notícias, informações para análise, considerando a intencionalidade do estudo.

O presente estudo foi dividido em seis partes. Na primeira, se define o conceito de cultura e educação. Na segunda, o design e a filosofia do design como ferramentas para a educação. Na terceira, se discute a temática do livro didático e na quarta os editais de distribuição deste objeto. A quinta sessão discorre sobre as questões de desigualdade e de igualdade e a última parte aborda a cultura de distribuição de livros didáticos no Brasil.

\section{CULTURA E EDUCAÇÃo}

A cultura é classificada como um conjunto de padrões de comportamento, crenças, conhecimentos e costumes que podem distinguir um grupo social. Cada cidade, estado ou país pode ter um tipo de cultura específico. Entretanto, por mais singular que ela seja, todas culturas seguem um mesmo tipo de sistema. No Brasil, por exemplo, seguimos o padrão capitalista, que ainda vive os resquícios de uma colônia historicamente explorada. A cultura original do país (a indígena), foi substituída e massacrada por seus civilizadores. Os ideais cristãos e capitalistas foram impostos e uma sociedade elitista, desigual e escravista determinou o domínio do poder e o caminho cultural a ser percorrido por esta nação classificada como de terceiro mundo. Ainda vivemos sobre este efeito, determinado por uma cultura elitista, capitalista e conservadora, que transmite aos seus cidadãos sistemas de modelos, que são caracterizados por um mercado geral de poder. A cultura de valor em vigor está presente nas tradições aristocráticas, através do conhecimento das elites formadas por "almas bem-nascidas, de gente que sabe lidar com as palavras, as atitudes e as etiquetas" (GUATARRI e ROLNIK 1996, pág. 20).

A cultura de massa pode ser definida através dos seus diferentes universos, como por exemplo a música, o cinema e a literatura e se caracteriza pela propagação através da indústria cultural. Esta, se dissemina de forma seletiva, através dos meios de comunicação de massa, caracterizando-se principalmente pela popularidade de determinados que representam a indústria cultural. No ano de 1982, Guatarri e Rolnik (1996) atribuem ao conceito de cultura de massa a característica reacionária e antidemocrática. Para os autores, este tipo de cultura se opõe a ideias de transformação da sociedade e defende princípios conservadores. Os autores ainda afirmam 
que "A cultura enquanto esfera autônoma só existe a nível dos mercados de poder, dos mercados econômicos, e não a nível da produção, da criação e do consumo real" (GUATARRI e ROLNIK, 1996, p. 15). A cultura age diretamente na subjetivação dos indivíduos, controlando os desejos e as necessidades de cada pessoa, processo denominado pelos autores de "cultura da equivalência" ou também de "sistemas de equivalência na esfera da cultura" (GUATARRI e ROLNIK, 1996).

A grande máquina capitalista também produz a subjetividade dos indivíduos. De forma silenciosa, age sobre o inconsciente e perpetua a ideia de manter hierarquias e de atribuir valor a tudo e a todos. (GUATARRI e ROLNIK, 1996). A submissão a ideologias geralmente ocorre sem uma tomada de consciência e questionamentos maiores. A cultura massificada está presente na forma em que a vida é conduzida pela sociedade capitalista, que tem como sua principal forma de dominação a repressão (DREYFUS e RABINOW, 2013). No Brasil, apesar de se viver nesta lógica capitalista e neoliberalista de produção de cultura de massa, pode-se identificar alguns fatos que marcaram a garantia do direito a educação para a sua população.

A exemplo disso, podemos mencionar a carta magna de 1988 , que marca a legalização de diversos avanços para a educação do país e foi conquistada através de uma mobilização sociedade civil (COUTO, 2008). Esta, criou o Plenário de Pró-participação Nacional Popular na Constituinte, que defende a escola pública e uma melhor educação para a sociedade com o conceito de escola gratuita, universal, democrática, comunitária e de qualidade. Fundamentada nos Artigos 206, 207 e 208 da Constituição Federal de 1988, que exige igualdade para acesso e a permanência na escola, traz também o conceito da arte do saber. De liberdade para aprender, ensinar, pesquisar e expressar o pensamento, ou seja, uma visão democrática para o ensino público (COUTO, 2008). Apesar do país ter muitas dificuldades na área da educação, ainda assim existem mobilizações que atuam e se preocupam com os direitos humanos, como por exemplo o envolvimento da UNESCO (Organização das Nações Unidas para a Educação, a Ciência e a Cultura). Além disso, as leis de incentivo, de distribuição e de produção de materiais didáticos, com o envolvimento de profissionais adequados para atuarem na sua elaboração, podem contribuir para o desenvolvimento da educação no país.

\section{O DESIGN COMO FERRAMENTA PARA A EDUCAÇÃO}

O design pode contribuir de forma impactante na área da educação, principalmente no que diz respeito aos "artefatos mediadores de aprendizagem" como por exemplo na projetação de livros didáticos, jogos educacionais ou ambientes virtuais. Pode também ser considerado como um caminho para resolver conflitos do campo educacional, agregando valor aos conteúdos a serem trabalhados e criando uma inovação na abordagem de formalização das disciplinas, através dos recursos que dispõe. De acordo com Coutinho e Lopes (2011), "o design é também a conceituação de ideias materializadas por meio do emprego de tecnologias" (COUTINHO e LOPES, 2011, p. 139). As autoras também ressaltam a importância da ferramenta do design para o ensino quando afirmam que o design gráfico é uma ferramenta essencial para o campo educacional.

$\mathrm{Na}$ área de atuação do Design, pode-se denominar como profissional envolvido na elaboração dos materiais didáticos o Designer Gráfico e/ou Designer Instrucional. A definição do primeiro está mais ligada às questões visuais (símbolos visuais e comunicação de informações através de palavras e imagens), e o segundo se relaciona diretamente a criação de soluções educacionais (CAVALCANTI e FILATRO, 2017). Portanto, para a elaboração do objeto em foco do 
presente estudo, o livro didático, pode-se ressaltar a importância dos profissionais da área do design. Estes podem contribuir de forma decisiva para a construção de um projeto gráfico bem definido, proporcionando a transmissão de conhecimento de forma articulada aos estudantes e professores que fazem o seu uso, considerando também os aspectos filosóficos de design, que se pode identificar no projeto de design e sobretudo, na ação e os efeitos sobre os usuários.

De acordo com Beccari, Portugal e Padovani (2017), a filosofia do design é uma área de estudos ainda incipiente, entretanto, pode ajudar o designer a compreender o que está projetando. Os autores propõem a filosofia do design, com o objetivo de ampliar as reflexões sobre o campo, realizando um pensamento complexo, múltiplo e reflexivo. Neste sentido, propõem seis eixos para o design e filosofia, os quais podemos aplicar diretamente no objeto de estudo deste trabalho: o livro didático. Os seis eixos apresentados pelos autores são: design e linguagem, design e sensibilidades, design e valores, design e conhecimento, design e realidade e por fim, design e cultura.

No primeiro eixo filosófico, design e linguagem, os autores afirmam que "O design é encarado como um articulador de significados" (p. 21), presente no campo da semiologia, dos significados da linguagem, dos objetos e das imagens. Ou seja, questões relacionadas à gramática visual e à retórica no design, fazem parte deste eixo filosófico do design e linguagem. O segundo eixo filosófico, de acordo com os mesmos autores, trabalha com o design e sensibilidades, onde o design é definido como um articulador de afetos e sensibilidades, na relação com a experiência estética e a percepção da beleza, através de seus produtos, objetos e imagens. O terceiro eixo, é definido pelos autores como design e valores, onde os princípios, as bases morais, as convicções dos projetistas e todo o ciclo de produção e tecnologias definem e fazem parte deste campo filosófico do design. O quarto eixo filosófico, é definido pelos autores como design e conhecimento. Neste campo, as questões são correspondentes ao conhecimento científico e técnico do designer, que através do seu projeto reproduz seus conhecimentos, intuições e os resultados de seus processos criativos. O quinto eixo, é definido como design e realidade, onde o design é um mediador de realidades e, por meio do design, se torna possível uma intervenção sobre os sentidos, sobre os diferentes modos de ser e enfrentar a realidade que se vive. Por fim, o último eixo filosófico é definido pelos autores como design e cultura. Neste campo, o design se entende como objeto sociocultural, que representa a percepção de uma determinada manifestação e a percepção relacionada aos seus aspectos culturais, assim como as fronteiras culturais entre design, arte e engenharia, sobretudo relacionando o design com as práticas de produção e consumo (BECCARI, PORTUGAL e PADOVANI, 2017).

\section{O LIVRO DIDÁTICO}

O livro didático é um recurso pedagógico que atua no processo de ensino-aprendizagem e, além de abordar os conteúdos tipicamente escolares, pode transmitir valores éticos, morais, sociais e culturais. Pode também ser definido como uma ferramenta cultural, porque, através do conteúdo transmitido, insere o estudante em um determinado contexto histórico-político. A maneira pela qual o trabalho é conduzido pelo professor influencia de forma direta a sua eficiência na transmissão do conteúdo. É neste contexto que a escola se torna um meio de transmissão onde a cultura é disseminada por meio do livro didático, no ambiente escolar (RAMIL 2014).

O livro didático pode ser definido como um artefato impresso em suporte de papel, que articula imagens e textos em formato sequencial, planejado, organizado. Ele é produzido para um 
público específico, que utilizará o material em situações didáticas, envolvendo alunos e professores. Sua principal função é a de transmitir saberes presentes a uma disciplina escolar (FREITAS, 2009). As formas de utilização deste tipo de material no ambiente escolar, "tornam-se um ponto de apoio essencial no processo de aprendizagem" (COUTINHO e LOPES, 2011, pág. 144). Com o passar dos anos, a produção destes materiais vem ganhando uma maior visibilidade e fortes investimentos, tendo em vista a grande parcela governamental de incentivo destinada ao segmento por meio dos programas de aquisição e distribuição de livros didáticos.

Diversos profissionais estão envolvidos no processo de produção e projetação de um livro didático. Entre eles, estão: editor, diagramador, autor, diretor de arte, designer, entre outros (HASLAM, 2010). Em geral, o editor é o principal responsável pelo projeto do livro, administrando as questões legais (porque é o detentor dos direitos autorais), de produção e de distribuição dos produtos impressos da editora. Entre os profissionais envolvidos no desenvolvimento do projeto de um livro didático, pode-se salientar a importância do designer gráfico, porque através do projeto gráfico se materializa o conteúdo do livro. Através das escolhas e intervenções no projeto do designer se dá a disposição dos conteúdos e a mensagem se materializa para o consumidor final. Sua atuação começa desde a escolha dos materiais e do formato do impresso, passando pelo desenvolvimento do leiaute, da tipografia, da elaboração ou escolha de imagens (fotografias ou ilustrações), até chegar nos tipos de acabamentos e de capa do livro (HASLAM, 2010). Todas estas escolhas e aplicações carregam os eixos filosóficos do design (BECCARI, PORTUGAL e PADOVANI, 2017), mencionados na seção anterior. Por exemplo, um livro muito pesado, ergonomicamente desconfortável que não se abre por inteiro (tipo de encadernação de costura) será difícil de ser manuseado (principalmente se o usuário for uma criança). A escrita neste material será comprometida. A sensação que a utilização deste material pode trazer para uma criança, influencia de forma direta na sua interação, podendo dificultar a realização das atividades e criar uma interação desfavorável ao seu uso e, consequentemente, à aprendizagem.

Entretanto, os livros didáticos elaborados para a submissão nos editais de distribuição gratuita do governo, não possuem em seu projeto gráfico apenas as escolhas realizadas pelo designer, editor ou diretor de arte da editora. Para os projetos serem aprovados pelos avaliadores, os livros devem conter requisitos formais para se enquadrar nos critérios de avaliação propostos pelo Sistema Educacional. Sendo assim, este pré-requisitos interferem diretamente no projeto gráfico e na atuação do designer e no resultado formal do impresso.

\section{OS EDITAIS DE DISTRIBUIÇÃO DE LIVROS DIDÁTICOS}

O principal responsável pela distribuição de livros didáticos gratuitos para as escolas públicas no Brasil é o Ministério da Educação e da Cultura (MEC). Representado pelo Fundo Nacional do Desenvolvimento da Educação (FNDE), possui um sistema que formaliza a rede de compartilhamento de materiais com o Plano Nacional do Livro Didático (PNLD). Através dos editais para as áreas de conhecimento e níveis específicos (por exemplo, 10 ano do Ensino Fundamental), as editoras cadastram os seus livros e concorrem a um rígido processo seletivo. Os livros aprovados pelos critérios do edital são divulgados pelo site oficial do PNLD, através do Guia do Livro Didático. Este guia serve como referência para a escolha do material a ser adotado pelas instituições e são designados pelos professores das escolas contempladas (FNDE, 2017).

Ao longo dos anos, diversos editais foram lançados e as exigências em relação às editoras, 
bem como a concorrência entre elas veem aumentando. Os conceitos e as abordagens culturais sofreram algumas evoluções com o passar do tempo, como por exemplo, no discurso e na mensagem subjetiva que as imagens e as ilustrações carregam. Atualmente a ideia de igualdade e inclusão é obrigatória na composição das obras selecionadas pelo PNLD. Entretanto, nem sempre foi esta a mensagem ideológica que os livros didáticos carregaram ao longo dos anos e pode-se considerar este fato como uma conquista social recente. Ainda assim, mesmo com o reconhecimento destes avanços nada está garantido, pois o discurso político oscila a cada mandato e o que representa o nosso país atualmente, demonstra uma tendência conservadora.

\section{DESIGUALDADE E IGUALDADE}

De acordo com Moreno (1999), nas imagens presentes nos livros didáticos do período que corresponde a produção dos anos 1990, os personagens masculinos representam a maioria das figuras. Generalizando, o autor afirma que eles realizam ações dinâmicas e exercem profissões importantes como a de médico, astronauta ou arquiteto. Já nas representações que aparecem a figura do feminino a mensagem da ação leva a atividades submissas e de organização do lar como por exemplo, lavar, costurar ou cozinhar. O discurso da mulher como a "bela, recatada e do $\operatorname{lar}^{\prime 1}$ era recorrente nas obras deste período.

De acordo com Faria (1994), nos anos 1970, era muito comum também o fato da mulher sofrer discriminação através dos livros didáticos. A autora realizou um estudo com os 35 títulos mais vendidos no ano de 1977, aplicando análises sobre o discurso apresentado pelos exemplares. $\mathrm{Na}$ opinião da autora, a maioria das obras apresenta a figura da mulher ligada a funções correspondentes a maternidade e ao cuidado do lar. Quando aparece realizando alguma profissão, que é raridade, está sempre relacionada com funções tipicamente femininas como, por exemplo, bordadeira, enfermeira, professora, cozinheira ou babá. $O$ trabalho doméstico realizado pelas mulheres, aparece nos exemplares analisados por Faria como uma função natural da mulher, numa relação de exploração sem remuneração de obrigação moral. A partir desta análise da autora pode-se afirmar que os eixos da filosofia do design que representam a linguagem, as sensibilidades, os valores, o conhecimento, a realidade e a cultura, representam de forma machista e discriminatória a figura do feminino.

A reflexão sobre funções sociais impostas pelas mensagens que os veículos de comunicação compartilham em seu discurso torna-se de extrema importância para a formação humana. A forma em que os livros, as revistas e a televisão apresentam os modos de ser menino e menina produzem e reforçam a oposição binária e estética entre homem e mulher. Um dos locais onde as reflexões sobre gênero se tornam necessárias e possíveis é no ambiente escolar (TAUFER, 2009). O peso informacional e a mensagem subjetiva presentes nos materiais escolares apresentam e reforçam o que a sociedade vivencia.

Em contraste a esta realidade descrita, onde os livros didáticos reforçavam uma visão machista e conservadora, encontramos uma nova forma de conduzir a produção editorial na atualidade, no segmento didático. Os editais dos principais programas de distribuição do Brasil carregam atualmente um discurso que exige de forma consistente uma diversidade étnica e social nas representações das imagens e das ilustrações dos livros didáticos. A exemplo do último edital

\footnotetext{
1 Termo utilizado para classificar a figura de Marcela Temer. Ver matéria disponível em http://veja.abril.com.br/brasil/marcela-temer-bela-recatada-e-do-lar/ Acesso em 14/10/2017
} 
de avaliação de obras didáticas (BRASIL, 2017) pode-se localizar no seu primeiro parágrafo de apresentação o nome da União, do MEC, da SEB (Secretaria de Educação Básica), da SECADI (Secretaria de Educação Continuada, Alfabetização, Diversidade e Inclusão) e do PNLD. No edital anterior a este (BRASIL, 2014), apresenta somente o nome do MEC, da SEB e do FNDE. Portanto, no edital publicado por último, pode-se inferir uma preocupação maior com as questões de diversidade e inclusão, a partir da identificação de integração com a União e SECADI já nas primeiras linhas apresentadas pelo documento. Além da apresentação, pode-se identificar esta estratégia de inclusão a partir do Anexo III do edital inferido (BRASIL, 2017) que afirma a exclusão imediata da obra que contenha as seguintes abordagens:

"Veicular estereótipos e preconceitos de condição socioeconômica, regional, étnico-racial, de gênero, de orientação sexual, de idade, de linguagem, religioso, de condição de deficiência, assim como qualquer outra forma de discriminação ou de violação de direitos humanos... doutrinação religiosa, política e/ou ideológica, desrespeitando o caráter laico e autônomo do ensino público... promover negativamente a imagem da mulher, desconsiderando sua participação em diferentes trabalhos, profissões e espaços de poder, desvalorizando sua visibilidade e protagonismo social... abordar a temática de gênero segundo uma perspectiva sexista não igualitária, inclusive no que diz respeito à homo e transfobia... Desconsiderar o debate acerca dos compromissos contemporâneos de superação de toda forma de violência, com especial atenção para o compromisso educacional com a agenda da não-violência contra a mulher... Não promover a educação e cultura em direitos humanos, desconsiderando os direitos de crianças e adolescentes, bem como o conhecimento e vivência dos princípios afirmados no Estatuto da Pessoa Idosa... Propor ação pedagógica voltada para desrespeito e desvalorização da diversidade, aos conceitos de sustentabilidade e da cidadania... Promover postura negativa em relação a imagem de afrodescendentes e dos povos do campo, desconsiderando sua participação e protagonismo em diferentes trabalhos, profissões e espaços de poder... Promover postura negativa em relação a cultura e história afrobrasileira e dos povos indígenas brasileiros, desvalorizando seus valores, tradições, organizações, conhecimentos, formas de participação social e saberes sociocientíficos, desconsiderando seus direitos e sua participação em diferentes processos históricos que marcaram a construção do Brasil, desvalorizando as diferenças culturais em nossa sociedade multicultural... Abordar a temática das relações étnico-raciais, do preconceito, da discriminação racial e da violência correlata, de forma não solidária e injusta... Desconsiderar a diversidade cultural, social, histórica e econômica do país nos textos, enfoques e exemplos utilizados nas obras".

Além destes aspectos presentes como requisitos para a aceitação das obras didáticas, pode-se apontar outros avanços teóricos referentes a inclusão e a diversidade como por exemplo, os cadernos da SECADI e da Unesco, presentes no site do MEC. Os seguintes cadernos, "Olhares Feministas" (2006), "Gênero e Diversidade Sexual na Escola: reconhecer diferenças e superar 
preconceitos" (2007), "Proteger para Educar: a escola articulada com as redes de proteção de crianças e adolescentes" (2007) e "Diversidade Sexual na Educação: problematizações sobre a homofobia nas escolas" (2009), revelam um pensamento mais aberto acerca das questões voltadas a um ponto de vista conservador. Vale ressaltar que o governo em vigência na época da publicação de todos estes materiais era o de ideais esquerdistas (PT). Estes materiais são recursos para qualquer professor ou até mesmo cidadão comum, interessado nos respectivos assuntos, para uma leitura reflexiva ou aplicação em sala de aula. Entretanto, no governo atual, que tomou o poder de forma ilegítima e possui uma bancada de caráter evangélico e conservador, pode-se especular que estes cadernos e editais correm risco de existência e validade.

Entretanto, pode-se observar uma tendência conservadora por parte do governo em vigor. Quando o atual presidente deste país, assumiu o poder no ano de 2016, uma das primeiras medidas que tomou foi a eliminação de diversos funcionários da SECADI ${ }^{2}$, secretaria responsável pela inclusão e diversidade, tendo esta atitude impactado de forma direta os funcionários encarregados pelo EJA, afetando todos os envolvidos com a educação de jovens e adultos, principalmente os estudantes. Outra atitude que demonstra um pensamento retrógrado do governo atual se comparado com o anterior é a medida provisória que defende a exclusão de disciplinas como artes, filosofia, educação física e sociologia do currículo obrigatório ${ }^{3}$. Inclusive no site oficial do FNDE é divulgado que no PNLD de 2018 não haverá a escolha de livros para o componente curricular de artes por "uma recomendação dada pela Secretaria de Educação Básica do Ministério da Educação". ${ }^{4}$ Fatos estes que trazem insegurança no que se diz respeito às conquistas que já tiveram ocorrido na educação brasileira. Ainda assim, mesmo com a construção dos cadernos da SECADI publicados, citados anteriormente, sabe-se que a sociedade ainda se caracteriza por visão excludente, valorizando o status e o poder.

Ainda muitas crianças e adultos sofrem com "bullying" e com a exclusão, ao tempo que agressores ganham força. Com o passar dos anos a probabilidade de suas atitudes perversas se desenvolverem e se estenderem para casos extremos. Por exemplo nas capitais onde moradores de rua são queimados ou até mesmo nas na falta de ética dos políticos que cometem diariamente injustiças com o orçamento público. Entretanto, mesmo com todos estes fatos impactantes ainda está em vigor a distribuição gratuita de materiais didáticos, conquista na educação nacional que ainda esta garantida.

\section{A CULTURA DE DISTRIBUIÇÃO DE LIVROS DIDÁTICOS}

O Brasil, apesar de ser o país que mais distribuí livros didáticos no mundo, está em 39o lugar no ranking da educação divulgado pela OCDE (Organização para a Cooperação e Desenvolvimento Econômico) $)^{5}$. A instituição avalia como requisitos para a educação o

\footnotetext{
2 Disponível em <http://brasil.estadao.com.br/blogs/vencer-limites/toda-equipe-da-secretaria-deeducacao-continuada-alfabetizacao-diversidade-e-inclusao-do-mec-foi-demitida/> Acesso em $14 / 10 / 2017$

${ }^{3}$ Disponível em http://odia.ig.com.br/brasil/2016-09-22/reforma-no-ensino-medio-dispensa-aulas-deeducacao-fisica-artes-e-espanhol.html Acesso em 11/10/2017

${ }^{4}$ Disponível em http://www.fnde.gov.br/programas/programas-do-livro/livro-didatico/escolha-pnld2018 Acesso em 14/10/2017

${ }^{5}$ Divulgado pelo Guia do Estudante Abril em 16/05/2017, disponível em:
} 
desempenho dos alunos, a média de tempo em que permanecem nas escolas e a porcentagem de estudantes que cursa o ensino superior. Apesar da distribuição ser aparentemente bem difundida no país, ainda pode-se apontar diversas falhas no desenvolvimento da educação que podem ocorrer por diversos motivos como por exemplo, a má distribuição de renda, a situação de pobreza das famílias e a desvalorização dos profissionais da área da educação.

Uma das razões que pode explicar o déficit na educação brasileira apesar da ampla distribuição de livros didáticos, e altos investimentos por parte do governo no mercado editorial é utilização inadequada dos materiais distribuídos gratuitamente. Geralmente, quando é oferecido algo de graça, a desvalorização é imediata. O ser humano valoriza aquilo que é caro, requisitado e de difícil acesso. Além disso, a formação dos professores também impacta diretamente na utilização dos materiais. De nada adianta ter acesso ao livro se ele não corresponde ao repertório do profissional que não consegue se apropriar do conteúdo. Dessa forma, fica impossível utilizar o recurso de forma adequada e esta explicação pode ser uma das hipóteses que demonstra uma possível falha no programa de distribuição.

Evidências que solidificam a especulação do parágrafo anterior, referente as possíveis falhas no programa de distribuição de livros didáticos, estão presentes em algumas reportagens na mídia. Estas matérias denunciam o descaso com os livros distribuídos pelo governo, a exemplo da reportagem exibida no site oficial de notícias da rede globo $(\mathrm{G} 1)^{6}$, que mostra mais de três mil livros didáticos descartados por uma escola de Santa Catarina no ano de 2014, sendo que alguns deles ainda estavam lacrados. Outro caso semelhante foi publicado por um dos principais veículos de comunicação do Rio Grande do Sul o $\mathrm{CLICRBS}^{7}$, onde mostra diversos livros que nunca foram utilizados, sendo descartados na coleta seletiva de Caxias do Sul no ano de 2015. Além destes dois casos, ainda outra matéria registrada no ano de 2016 pelo site LIBERDADE NEWS ${ }^{8}$ denunciando o mesmo tipo de incidente na Cidade de Teixeira de Freitas na Bahia. Fatos estes revoltantes, que revelam uma incoerência grave, provando como o dinheiro público é mau administrado e evidenciando a falta de compromisso de algumas instituições.

\section{CONSIDERAÇÕES FINAIS}

Este estudo permitiu uma reflexão acerca de temas políticos e sociais, ligados a educação. Porém, não pretende trazer uma verdade, e sim pontos de vista, seguindo uma perspectiva igualitária e inclusiva. Quando ainda no ano de 1982, Guattari e Rolnik afirmaram que "As pessoas do PT, em particular o Lula, não participam de determinada qualidade de cultura dominante" devido ao seu "estilo e etiqueta" e que estas não fazem parte da "cultura capitalística dominante", entendemos o que está por trás de toda a incompreensão presentes nos defensores de direita que não aceitam este tipo de concorrência política. Sobretudo, a partir das evidências trazidas por este estudo, pode-se dizer que estes políticos, que representam um estilo "inferiorizado" e de "baixa

\footnotetext{
https://guiadoestudante.abril.com.br/universidades/brasil-esta-em-penultimo-lugar-em-ranking-dequalidade-na-educacao/> Acesso em 14/10/2017

${ }^{6}$ Disponível em: <http://g1.globo.com/bom-dia-brasil/noticia/2014/08/mais-de-3-mil-livros-didaticosnovos-sao-jogados-fora-em-santa-catarina.html> Acesso em 13/10/2017.

7 Disponível em: <http://pioneiro.clicrbs.com.br/rs/geral/cidades/noticia/2015/12/livros-didaticossao-jogados-no-lixo-seletivo-em-caxias-do-sul-4925850.html> Acesso em 12/10/2017.

8 Disponível em: <http://liberdadenews.com.br/index.php/policia/14696-denuncia-livros-didaticosjogados-fora-revoltam-moradoresem-teixeira-de-freitas\#> Acesso em 12/10/2017.
} 
cultura", são capazes de promover a educação e a inclusão de uma forma muito mais digna e ética do que os militantes de direita, regados pelos princípios neoliberais.

O discurso presente nos valores e nas imagens disponíveis nos livros didáticos é uma forma de refletir alguns valores da sociedade. Ainda estamos vivendo nos nossos editais de distribuição uma visão igualitária, fruto das conquistas do governo esquerdista do passado. Qual é a garantia de que este discurso irá se manter, tendo em vista os retrocessos políticos que vivemos? A exemplo do fechamento da Queermuseu no Santander Cultural em Porto Alegre (2017), por pressão de um movimento conservador (MBL), uma exposição de arte legítima, fechada por pessoas que nada entendem do assunto e ainda reverbera, dividindo opiniões políticas de forma impactante.

Finalizando este artigo, se lança uma pergunta, como proposta de reflexão sobre o assunto discorrido: o que aguardam as políticas públicas para a nossa educação nos próximos anos?

\section{REFERÊNCIAS}

BECCARI, Marcos. PORTUGAL, Daniel B. PADOVANI, Stephania. Seis eixos para uma filosofia do design. Estudos em Design. Revista (online). Rio de Janeiro: v. 25 | n. 1 [2017], p. 13 - 32 | ISSN 1983-196X

BRASIL, Ministério da Educação. Fundo Nacional de Desenvolvimento da Educação. Secretaria de Educação Básica. Edital de Convocação 02/2014 - CGPLI. Edital de Convocação para o Processo de Inscrição e Avaliação de Obras Didáticas para o Programa Nacional do Livro Didático, PNLD 2016.

BRASIL, Ministério da Educação. Fundo Nacional de Desenvolvimento da Educação. Secretaria de Educação Básica. Edital de Convocação 01/2017 - CGPLI. Edital de Convocação para o Processo de Inscrição e Avaliação de Obras Didáticas para o Programa Nacional do Livro Didático, PNLD 2019.

CAVALCANTI, Carolina Costa. FILATRO, Andrea Cristina. Design Thinking na educação presencial, a distância e corporativa. São Paulo, Saraiva: 2016.

COUTINHO, Solange Galvão. LOPES, Maria Teresa. Design para a educação: uma possível contribuição para o ensino fundamental brasileiro. In: BRAGA, Marcos da Costa (org.). O papel social do design gráfico: história, conceitos \& atuação profissional. São Paulo: Editora Senac São Paulo, 2011.

COUTO, Rita Maria de Souza. Escritos sobre ensino de design no Brasil. Rio de Janeiro: Rio Books, 2008. 96 p. ISBN 978-85-61556-01-3

DREYFUS, Hubert L. RABINOW, Paul. Michael Foucault: uma trajetória filosófica. 2. ed., rev. - Rio de Janeiro: Forense Universitária, 2013.

FARIA, Ana Lúcia G. de. Ideologia no livro didático. 11. ed. São Paulo: Cortez, 1994. 96p

FNDE, Ministério da Educação. História. 2017. Acesso em 07/10/2017, disponível em: http://www.fnde.gov.br/acesso-a-informacao/institucional

FREITAS, Itamar. Livro didático de história: definições, representações e prescrições de uso. In: OLIVEIRA, Margarida Dias de; OLIVEIRA, Almir Flélix Bueno de. Livros didáticos de História: 
escolhas e utilizações. Natal: Editora da UFRN, 2009. pp. 11-19

GUATTARI, Felix; ROLNIK, Suely. Micropolítica: cartografias do desejo. 4. ed. Petropolis: Vozes, 1996.

HASLAM, Andrew. O livro e o designer II: como criar e produzir livros. 2. ed. São Paulo: Rosari, 2010.

MORENO, Montserrat. Como se ensina a ser menina. Campinas: Moderna - Editora da UNICAMP, 1999.

MARQUES, Mara Rúbia A. Imagens Femininas e Masculinas no Livro Didático: subsídios para um debate teórico- metodológico. Olhares Feministas / Hildete Pereira de Melo, Adriana Piscitelli, Sônia Weidner Maluf, Vera Lucia Puga (organizadoras). - Brasília : Ministério da Educação : UNESCO, 2006. 510 p. - (Coleção Educação para Todos ; v. 10) Disponível em: http://portal.mec.gov.br/index.php?option=com_docman\&view=download\&alias=639-

vol10feministas-pdf\&category_slug=documentos-pdf\&Itemid=30192

NAKAMOTO, P.; A configuração gráfica do livro didático: um espaço pleno de significados. Campinas, CP: [s.n.], 2010.

RAMIL, Chris de Azevedo. Os livros didáticos e a linguagem visual gráfica: um estudo de caso dos anos 1970. X ANPED SUL, Florianópolis, outubro de 2014.

SAMPIERI, Hernándes; COLLADO, Fernández, LUCIO, Baptista. Metodologia de Pesquisa. Porto Alegre: Penso, 2013.

TAUFER, Isabel Cristina Brandão. Representações de gênero no livro didático de ciências nos anos iniciais do ensino fundamental. Universidade Federal do Rio Grande do Sul. Faculdade de Educação. Especialização em educação, sexualidade e relações de gênero. Trabalho de conclusão de especialização. 2009. Acesso em 21/09/2017. Disponível em: http://hdl.handle.net/10183/21847

PISA, 2017. Disponível em: https://www.compareyourcountry.org/pisa/country/bra?lg=en 